\title{
O cronótopo do hotel e a formação da memória em O retorno, de Dulce Maria Cardoso
}

\author{
The hotel chronotope and the formation of memory in O retorno \\ by Dulce Maria Cardoso
}

\author{
ANA FILIPA PRATA \\ Universidade de Lisboa - Lisboa - Portugal
}

\begin{abstract}
Resumo: Neste artigo analisam-se os processos narrativos que dão conta da formação da memória, em articulação com o cronótopo do hotel, na obra $O$ retorno, de Dulce Maria Cardoso. Discute-se, através da figura da repetição e dos seus desdobramentos retóricos, a negociação e o conflito entre vários discursos, espaços e tempos expostos no relato do protagonista Rui, que constata a impossibilidade de retornar, simultaneamente, ao passado e a Portugal, através do questionamento dos limites da linguagem. Procura-se ainda demonstrar como o paradoxo de voltar a um lugar/tempo que já não existe é amplificado na estadia no hotel, o microcosmos que dá corpo à experiência da espera e do trânsito dos retornados entre a partida das ex-colónias e o início de uma nova vida na metrópole.
\end{abstract}

Palavras-chave: Memória; Literatura pós-colonial; Retornados; Cronótopo; Hotel

\begin{abstract}
This article focuses on the narrative features addressing the formation of memory, in relation to the hotel chronotope, in O retorno, by Dulce Maria Cardoso. Through the analysis of repetition and its rhetoric variations, it examines the negotiation and the conflict underlying the several textual, spatial and temporal issues exposed in the account of its protagonist Rui, who realizes the impossibility of returning to the past and, at the same time, to Portugal, by questioning the limits of language and discourses. It aims to demonstrate how the paradox of returning to a place/time that no longer exists is amplified in the stay at the hotel, the microcosm shaping the experience of waiting and of being in transit went through by the retornados, while leaving the ex-colonies and starting a new life at the metrópole.
\end{abstract}

Keywords: Memory; Postcolonial literature; Retornados; Chronotope; Hotel

Passados quarenta anos sobre a revolução de Abril de 1974, a consequente independência dos territórios ultramarinos e a tão desejada aproximação de Portugal à Europa moderna e democrática, purgam-se ainda, quase meio século depois, as trágicas vivências da ditadura, da guerra e dos seus traumas, da descolonização apressada, bem como do retorno de milhares de portugueses à pátria. O passado colonial tem estado presente na literatura portuguesa desde as décadas de 70 e 80 , até aos dias de hoje, como tema predominante. Numa primeira fase da escrita da guerra e da descolonização, destacamse grandes vozes contemporâneas como as de António Lobo Antunes ou Lídia Jorge, ao lado de Manuel Alegre, Hélder Macedo ou João de Melo, autores que tomaram o "regresso" de África como motivo de reflexão acerca das ideias de nacionalismo, imperialismo e da sua decadência no âmbito do questionamento, por um lado, da perda de um território físico e simbólico e, por outro, de um novo posicionamento de Portugal em relação a uma comunidade europeia. Sendo mais do que uma literatura de guerra, esta é uma escrita sobre "o espaço no qual se manifesta o violento processo de desterritorialização e re-territorialização, marcados pela perda individual e colectiva" (CALAFATE RIBEIRO, 2002, p. 187)1. Há, contudo, uma natural evolução no tratamento da matéria colonial e das perspectivas a partir das quais se (re)escrevem os diferentes episódios deste passado. O momento presente é, sem dúvida, significativo para a complexificação deste capítulo ainda por encerrar da recente história portuguesa e prova disso são as várias

\footnotetext{
1 Tradução minha.
} 
publicações, filmes e documentários relativos a este tema que têm vindo a lume nos últimos anos².

Como já foi notado por Isabel Ferreira Gould (2008, p. 183), a partir da década de 90 começaram a emergir as vozes e os testemunhos dos ex-colonos e acentuou-se o tom memorialístico no relato da experiência da colónia. Sheila Khan (apud RIBEIRO, 12/08/2010), por sua vez, dá conta da existência de uma nova literatura "de retornados", escrita por aqueles que, muitas vezes sem nunca a terem antes visitado, desembarcaram na "metrópole" e durante décadas sofreram em silêncio o peso da sua condição de "retornados" e do rótulo pejorativo que lhes foi atribuído pela sociedade portuguesa no difícil processo de digestão do passado colonial. Este assunto tabu - o retorno -, como muitos outros que ecoam no imaginário contemporâneo relativo à presença portuguesa em África ${ }^{3}$, começa agora a ser explorado de forma significativa muitas vezes pelos próprios protagonistas ou pelos seus filhos, sendo essa a perspectiva que muda o relato da vivência colonial portuguesa feita até então, acrescentando-lhe outras leituras e complexificando o seu sentido.

É certo que o momento presente em que se encontra Portugal, tendo em conta a nova variante da mesma crise ligada à sua condição periférica na Europa, poderá justificar alguma nostalgia no regresso ao passado em África, à reconstituição de uma identidade do povo português que, simultaneamente sofredor e empreendedor, saberá mais uma vez superar as dificuldades que atravessa ${ }^{4}$. Porém, é certo também que, com mais ou menos qualidade literária, mais ou menos tendências conservadoras ou nacionalistas, estas obras constituem discursos e documentos importantes para a compreensão dos contornos do retorno propriamente dito, enquanto episódio histórico, dos portugueses à cabeça (desfeita) do império ${ }^{5}$. Passados quarenta anos desde o regresso das caravelas, os retornados começaram finalmente a "abrir o baú” (RIBEIRO, 12/08/2010). Trata-se, neste momento, de apresentar uma outra versão dos factos, paralela à do discurso oficial e político, e de introduzir um novo episódio na história colonial, contado por outras vozes que dão conta das experiências e consequências subjetivas do fim do colonialismo português na vida daqueles que nele estiveram diretamente envolvidos, não só enquanto colonos, mas também enquanto emigrantes que haviam abandonado Portugal em busca de melhores condições de vida, nos então territórios ultramarinos. Como explica Isabel Ferreira Gould, em declarações registadas por Raquel Ribeiro no suplemento "Ípsilon" do jornal Público, nesta literatura de retornados apresenta-se a colónia em toda a sua complexidade, mas através de uma visão muitas vezes nostálgica. Estas obras que surgem são, portanto, exemplos do que a investigadora considera "narrativas de decantação, ou seja, textos escritos na primeira pessoa sobre memórias que estão estruturadas entre uma visão crítica do colonialismo e a necessidade de exaltar, para o bem e para o mal, as figuras fundamentais da identidade dos sujeitos da narrativa" (apud RIBEIRO, 12/08/2010). Retrata-se "[a] nossa relação com a casa, o espaço e o tempo, ansiando por um lugar de pertença. [Retratase] a nostalgia pelo perdido, pelo que África poderia ter sido, e pelo que não tínhamos e queríamos ter tido" (apud RIBEIRO, 12/08/2010). Esta vertente da escrita da memória colonial, na medida em que também é uma memória dos afectos, está consequentemente ancorada numa importante dimensão espacial cuja estruturação simbólica é questionada.

É neste contexto que surge o romance $O$ retorno, de Dulce Maria Cardoso, publicado em 20116 , e com ele um exercício literário sobre essa outra forma decantada de olhar para o passado colonial e para o retorno abrupto e descoordenado de milhares de famílias a Portugal. Nesta obra, a escrita da memória e da perda constrói-se com base nos inúmeros discursos que se referem ao passado, sendo marcada por uma certa humanização da tragédia que diz respeito, não apenas à massa dos retornados em geral, como uma colectividade, mas à vida singular de um indivíduo que passou pela experiência do abandono da

2 Nos últimos anos foram publicados vários livros sobre este tema, nomeadamente, Fala-me de África, de Carlos Vale Ferraz, (Casa das Letras, 2007), Os dias do fim, de Ricardo de Saavedra (Casa das Letras, 2008), Os retornados. Um amor nunca se esquece, de Júlio Magalhães (A Esfera dos Livros, 2008), Angola, terra Prometida, de Ana Sofia Fonseca (A Esfera dos Livros, 2009), Cadernos de memórias coloniais, de Isabela Figueiredo (Angelus Novus, 2009), A balada do ultramar, de Manuel Acácio (Oficina do Livro, 2009), Os pretos de Pousaflores, de Aida Gomes (Dom Quixote, 2011). Também surgiram algumas séries de televisão, "Regresso a Sizalinda" (RTP, 2008) e "Depois do adeus" (RTP, 2013) e um programa radiofónico, "Começar de novo" (Antena 1, 2013).

3 Faço aqui referência ao recente e premiado filme de Miguel Gomes, Tabu (2012), cuja história se centra nas memórias de crime e adultério da portuguesa Aurora em Africa, reveladas pelo seu ex-amante, depois da sua morte solitária e precedida por episódios de demência em Lisboa.

4 Num recente artigo intitulado "Portugal e o império. Memórias de retorno ou retornos da memória”, Catarina Isabel Martins chama a atenção para o perigo destes discursos, alegando que podem preencher um vazio ideológico para fazer face à difícil crise económica. Não deixa, contudo, de afirmar que as histórias dos retornados merecem e precisam de sair do silêncio, sendo que o seu contributo "[...] pode ser, exatamente, o de mostrar a complexidade do colonialismo português e das suas diferentes formas de materialização em tempos e contextos geográficos e sociais específicos" (MARTINS, 2013, p. 10).

5 É preciso não esquecer que a condição de "retornado" está estabelecida política e juridicamente e "concerne àquele que mantendo a sua nacionalidade portuguesa, tendo residido nas ex-colónias, nasceu na ex-metrópole, ou possui ascendentes até ao terceiro grau daí naturais (MACHADO, 2011, p. 2). Como tal, o retornado e o retorno devem ser considerados, respectivamente, como figura e episódio histórico concretos. Em 1975, foram criadas várias instâncias políticas, nomeadamente o IARN (Instituto de Apoio aos Retornados), com vista a organizar e acautelar o repatriamento e realojamento destes portugueses recém-chegados das colónias. Não existem números concretos, mas estima-se que tenham retornado a Portugal entre quinhentos mil a um milhão de indivíduos, na sequência da independência dos territórios ultramarinos (cf. MACHADO, 2011, p. 2).

6 O retorno foi publicado no Brasil em 2012, também pela editora Tintada-China. Acaba agora de ser lançada a sua tradução italiana (Il ritorno, Voland/Feltrinelli, 2013). 
casa, da desagregação do núcleo familiar e da adaptação a um novo território hostil. Este romance assume a forma de um testemunho inspirado na experiência autobiográfica da própria autora ${ }^{7}$, cujo protagonista é Rui, um rapaz de nove anos que, por um lado, relata e personifica ${ }^{8}$ os efeitos da catástrofe que foi o retorno e, por outro, dá conta dos mecanismos de gestão da própria imanência dessa catástrofe na vida do adolescente em que ele se está a transformar.

Segundo Isabel Ferreira Gould, a "decantação chama a atenção para o passado, para o processo de seleção e representação da memória e para a problemática da validação do presente mediante o resgate de experiências passadas" (GOULD, 2008, p. 184) ${ }^{9}$. Em O retorno, este processo de filtragem e de negociação entre passado e presente destaca-se pela forma como é problematizado através de processos narrativos em articulação com o cronótopo do hotel, que fixa a narrativa na dimensão precária da espera e do trânsito. Se no relato de Rui sobressai uma permanente comparação entre passado e presente, entre o que é contado pelos outros e o que ele observa, o recurso a esta lógica binária contém em si a sua própria erosão, na medida em que é convocada para questionar as fronteiras entre o(s) discurso(s) e a vida real. Nesta obra, reflete-se sobre o instaurar de uma dúvida, sobre a perda da inocência na experiência do caos e olha-se para a colónia e para a metrópole, não apenas de uma outra forma, mas de um outro lugar, a partir do qual se desenha um ponto de fuga que condiciona uma outra perspectiva sobre os acontecimentos. O hotel, que constitui uma plataforma de trânsito prolongando, em alguns casos por vários anos, da ponte aérea LisboaLuanda é, no relato de Rui, o lugar onde se materializa a descoberta da imprevisibilidade da vida, bem como o reconhecimento da instabilidade identitária, assente numa dimensão precária da linguagem. Este romance concentra-se consequentemente na desconstrução das dicotomias e da univocidade dos discursos, enfatizando o diálogo e o conflito entre vários elementos temporais e espaciais que se amplificam no cronótopo do hotel, o palco para onde confluirão várias personagens e histórias, todas elas perpetuando-se no impasse da espera e da incerteza que começa no momento da partida de Angola.

$O$ retorno foca o momento entre a vida na colónia e a nova vida na metrópole, desde a partida de casa até à saída do hotel, sendo que a narrativa sublinha, logo no seu incipit, o período de expectativa e de suspeição sobre o qual se deterá até ao fim:

Mas na metrópole há cerejas. Cerejas grandes e luzidias que as raparigas põem nas orelhas a fazer de brincos. Raparigas bonitas como só as da metrópole podem ser. As raparigas daqui não sabem como são as cerejas, dizem que são como as pitangas. Ainda que sejam, nunca as vi com brincos de pitangas a rirem-se umas para as outras como as raparigas da metrópole fazem nas fotografias. (CARDOSO, 2011, p. 7)

Encetando a narração com uma frase adversativa, a voz de Rui expõe o conflito original associado à procura de uma aceitação e justificação para a nova etapa na sua vida e argumenta em favor da metrópole, cuja imagem idílica é transmitida pelos discursos oficiais, pelas fotografias e pelas memórias longínquas da terra de origem dos seus pais. A ideia de conhecer a metrópole atraente e sofisticada, onde há raparigas bonitas e cerejas, serve de discurso compensatório para o abandono da casa. Porém, este vai sendo progressivamente desconstruído ao longo do relato da descoberta de Lisboa, assemelhando-se a sua função narrativa à de uma epígrafe que vai sendo glosada ao longo do romance, perdendo cada vez mais a sua intensidade afirmativa e justificativa, para se transformar precisamente naquilo que antecipa, a sua antítese. A distância entre esta caracterização positiva da metrópole e o prenúncio da descoberta de uma cidade cinzenta, fria e habitada por pessoas tristes, mede-se pela experiência do choque e da incompreensão perante o rápido evoluir dos acontecimentos em Luanda, que se reproduz no silêncio e na incapacidade de nomear. O discurso de Rui, marcado por sucessivas catacreses ${ }^{10}$, revela a insistência numa rotina forçada de domingo, na repetição de gestos quotidianos e de pormenores prosaicos, como uma tentativa de agarrar o que resta ainda da vida e da casa que se desfazem: "Insistimos em pormenores insignificantes porque já começámos a esquecer-nos" (CARDOSO, 2011, p. 8). Neste primeiro capítulo do livro, o mais longo e que corresponde às últimas horas passadas em casa, são apresentados ainda outros elementos importantes da narrativa, nomeadamente a caracterização de cada um dos elementos da família (a doença da mãe, a coragem do pai, a suposta homossexualidade do tio Zé); a sua história oficial, contada como se fosse matéria de catequese ou

\footnotetext{
Cf. texto lido pela autora Dulce Maria Cardoso, pelo lançamento do seu livro $O$ retorno: https://retorno.facebook.com/photo.php?fbid=1015088 $3840720315 \&$ set $=$ a.310820615314.333183.301684475314\&type $=1 \&$ th eater. Acesso em 28 Out. 2013.

8 O nome próprio Rui, segundo a autora, é uma alusão ao verbo 'ruir' e à 'ruína' da sua própria identidade.

9 Tradução minha.

10 "O pai não era assim antes de isto acontecer. Isto são os tiros que se ouvem no bairro acima do nosso. $\mathrm{E}$ as nossas quatro malas por fechar na sala. [...] Agora já não há ninguém para visitar-nos mas mesmo antes de isto ter começado era raro termos visitas" (CARDOSO, 2011, p. 7-8); "Apesar de ser o último dia que passamos aqui, nada parece assim tão diferente. Almoçamos sentados à mesa da cozinha, a comida da mãe continua a não ser saborosa, temos calor e a humidade do cacimbo faz-nos transpirar. A única diferença é que estamos mais calados" (CARDOSO, 2011, p. 9). Destaques meus.
} 
recordada através das fotografias dos avós; a chegada da mãe a África para se casar com o pai; a última passagem de ano em Luanda, de 74 para 75, e a esperança de que tudo correria bem apesar da revolução; e, enfim, a desilusão que foi provar as cerejas, imagem através da qual a metrópole irradiava o seu esplendor:

Quando abriram a encomenda da metrópole a minha irmã e eu vimos cerejas pela primeira vez, tinham chegado velhas e mirradas [...]. A mãe comeu as cerejas com tanto prazer que a minha irmã e eu ficámos convencidos que as cerejas eram a fruta mais deliciosa do mundo, não há nada tão bom com as cerejas, repetia a mãe, mas não tinha razão, não deve haver nada tão deliciosamente mal saboroso como as cerejas. (CARDOSO, 2011, p. 39)

Todos estes episódios vão sendo introduzidos metonimicamente, através da associação de ideias que se vão sucedendo no discurso de Rui, como se fossem justamente cerejas que se vão comendo compulsivamente, umas a seguir às outras: uma ideia, um nome ou uma referência fazem recordar os momentos dispersos do passado na presença dos factos fraturantes que testemunha. Neste premente afluxo de informação pode ler-se uma tentativa de cristalizar a história e a identidade da sua família nas últimas horas antes da partida para a metrópole, através de um processo de rememoração inconsciente, contendo já todavia o prenúncio do desencanto e da perda evocados na imagem das cerejas. As dúvidas de Rui ganham dimensões progressivamente maiores à medida que se desenvolve uma heterogeneidade discursiva derivada, não apenas desta acumulação de histórias, mas também da convivência das suas várias versões. Para além da sua própria voz, irrompem no seu relato as palavras dos seus pais e irmã, as histórias do tio Zé e as comunicações oficiais. Estes diferentes ecos são incorporados no seu testemunho, que vai sintetizando as suas lembranças dispersas, arquivando-as na sua memória em construção, onde se vão realojando à medida que Rui as reutiliza para reconstruir a história, na busca constante de uma justificação para os acontecimentos.

Este entrecruzamento de vozes e imagens é particularmente interessante no segundo capítulo do livro, dedicado à descrição do aeroporto de Luanda, antes da saída do avião para a metrópole. O momento da partida da família é colocado em contraponto à captura do pai, através de um processo narrativo que faz coincidir o eco da sua detenção com o presente que se relata, sublinhado o choque causado pela fractura da unidade familiar. Rui encerra cada uma das anotações que faz à cena caótica observada no aeroporto com imagens da captura do pai. Cada parágrafo é rematado com um frase curta, fazendo referência a esse momento traumá- tico. ${ }^{11}$ Esta estrutura formal traduz os ecos ou réplicas que eclodem na cabeça e no discurso do Rui, como o reflexo do que observa na partida para a metrópole. Assim, "envolta na mesma poeira que não assenta", a família é separada e segue caminhos opostos. Logo nestas primeiras páginas, somos levados a concluir, com Rui, que no meio de tantas vozes e pontos de vista, "quase nada do que se dizia [era] verdade" (CARDOSO, 2011, p. 53): as cerejas, a imagem idílica e requintada da metrópole, a boa convivência entre brancos e negros, ou a esperança no crescimento de Angola como uma nação multicultural. Para além disso, e como culminar desta desilusão e incompreensão perante a imagem desfeita da realidade, a prisão do seu pai representa uma quebra total da harmonia e da lógica temporal, como uma sucessão de eventos encadeados e consequentes.

Esta forma de narrar os acontecimentos enfatiza, por um lado, a necessidade premente de Rui em conservar a memória e, por outro, subordinada a um "mas" inaugural, sublinha a atitude de suspeição constante instaurada na sua vida, na sequência da experiência do imprevisível. O seu relato dá conta da duplicidade inerente à própria ideia de repetição, identificada por Lacan (1973, p. 5362) através dos conceitos aristotélicos de automaton e tuché. No seu seminário XI, Lacan explica que, se por um lado o automaton aponta para os mecanismos de desdobramento automático do inconsciente, i.e. o retorno, o regresso, ou a insistência dos signos através dos quais somos comandados pelo princípio de prazer, a tuché corresponde à repetição no seu encontro com o real, onde ela se produz (cf. LACAN, 1973, p. 54). Da mesma forma, o relato de Rui é motivado por uma tendência para a estabilização e compensação da perda, funcionando a repetição como um artifício de controlo; porém, ao mesmo tempo, traduz um encontro falhado com o real, traumático, na medida em que enuncia algo de novo. Rui quer insistir naquilo que começa a esquecer, mas o seu discurso revela progressivamente essa impossibilidade, pois nunca se repete o mesmo, porque ele é sempre diferente. O seu relato posiciona-se "para além do princípio de prazer", enquanto fenómeno discursivo que dá conta da experiência da "neurose traumática" que, na análise de Freud, se manifesta através do medo e da dúvida (FREUD, 2006, p.315). A repetição, sob a

\footnotetext{
1 "O jipe desaparece depois da casa da Editinha.", "As mãos do pai amarradas às costas.", "Vámo matáti cum tuá arma e tuá bala.", "A poeira demora a assentar.", "A balalaica branca do pai ensopada de sangue.", "O isqueiro Ronson Varaflame caído ao pé do canteiro.", "A mãe de braços caídos no fim da rua.", "O sangue do pai no asfalto.", "Os vasos da escada tombados.", "O pai metido à força no jipe.", "As mãos do preto no braço do pai.", "A minha irmã sem conseguir descer as escadas.", "A Pirata a ganir com o pontapé do preto.", "Os olhos aflitos do pai.", "Os pretos a rirem quando o jipe arranca.", "A arma do pai nas mãos do preto.", "A arma do pai apontada à cabeça.", "A mãe a correr por dentro da poeira que não assenta" (CARDOSO 2011, p. XX-XX).
} 
forma de associação de ideias ou através de processos de desdobramento discursivo, surge, portanto, nesta narrativa como mecanismo retórico que reproduz esse questionamento e estranhamento em relação ao valor da verdade. Nesta medida se compreende também o recurso à imaginação, que não é mais do que uma variante da mesma figura da repetição e, a dado momento no hotel, Rui fantasia sobre o que poderá ter acontecido ao pai, quando foi raptado ainda em Luanda, no dia da viagem da família para Lisboa: "Estou a inventar, tenho de estar a inventar, ultimamente não faço outra coisa. Deve ser por estar neste hotel" (CARDOSO, 2011, p.90).

Os pensamentos soltos e contraditórios invadem o seu relato, sendo ele constituído por uma série de fragmentos que vêm de espaços e de tempos diferentes, convergindo todos para um mesmo ponto, sem uma ordem prévia. $\mathrm{O}$ ciclo causa-consequência foi abalado e o desastre e os seus efeitos são narrados quando se procede ainda à tentativa da sua compreensão. Neste aspecto, a experiência do choque relatada por Rui questiona a possibilidade de escrever na sequência de uma catástrofe e da experiência do inesperado, aproximando-se da problemática da literatura de testemunho. Segundo Márcio Seligmann-Silva (2003), a narrativa de testemunho coloca-se simultaneamente sob o signo da possibilidade e da impossibilidade ${ }^{12}$. Há, por um lado, uma necessidade de narrar a experiência vivida e, por outro, o reconhecimento da insuficiência da linguagem para dar conta da descrição dos factos. No seu relato, Rui expõe precisamente essa resistência entre a vontade de se situar na sua história e a dificuldade em encontrar para ela uma versão coesa, verosímil e que, simultaneamente, justifique a mudança operada na sua vida. As dúvidas acerca da sua capacidade em lidar com o imprevisto e com a interrupção de uma vida de projetos e de aspirações, que se tomava como garantida, colocam-se em forma de interrogação: como sobreviver ao medo de não ser capaz de "pensar numa coisa de cada vez"(CARDOSO, 2011, p. 267)?

Incertezas e questões vão desdobrar-se e ganhar uma amplitude maior na segunda parte da narrativa, a mais longa, e que tem como palco o hotel de cinco estrelas no Estoril. Neste lugar, prolonga-se e complexifica-se o sentimento de incompreensão perante os factos, associado à experiência de transição entre tempos, num espaço que é ele próprio um lugar de fronteira, um lugar entre vários espaços simbólicos: Angola e Portugal, a casa de Luanda e a casa/cave de Lisboa. Não só pela experiência de trânsito associada a este sítio, mas também pela percepção da dimensão temporal da espera que ele proporciona, relata-se a partir do (e no) hotel a descoberta de uma realidade distorcida, quase invertida, que resulta numa confusão da ordem representacional, contribuindo para o efeito de estranhamento e de perplexidade aos olhos de um jovem que até então tinha as ideias bem estruturadas acerca dos lugares de pertença dos objetos, das situações e das suas personagens. O hotel, enquanto cronótopo de ruptura associado ao "limiar" (threshold) analisado por Bakthin (1981, p.248), é um território de lutas de ordens discursivas e simbólicas, pois pela sua natureza relacional e comunicante é também um espaço de crise ${ }^{13}$. Ao contrário da casa, que na análise poética de Bachelard (1957) é concebida enquanto lar e representa a harmonia e a segurança (o que nem sempre é verdade, pois pode também ser um espaço de oposições), o hotel materializa a instabilidade das fronteiras entre o universo privado e público, entre identidade e alteridade, entre passado e presente. Nesta narrativa, o hotel reproduz ainda a complexa experiência de estar entre dois territórios e dois países que, de alguma forma, já foram o mesmo. $\mathrm{O}$ espaço do hotel caracteriza-se pela contaminação, figura retórica simultaneamente pós-moderna e pós-colonial, e pela transgressão, na medida em que dá conta da subversão inerente a estes falsos binarismos.

A primeira percepção do hotel no Estoril, espaço que Rui e a sua família não tinham o hábito de frequentar, é a de um lugar hostil, onde são recebidos por uma diretora, cujo discurso falsamente solidário cabe no espaço de um capítulo reduzido a um único parágrafo, manifesto num exercício de contração formal que sublinha o seu autoritarismo. As regras do hotel são apresentadas sob a justificação repetida "das circunstâncias terríveis e dos tempos conturbados" (CARDOSO, 2011, p. 67). Neste "estado de emergência", Rui e a sua família não são recebidos como os "hóspedes normais," para os quais está reservado o último piso do edifício. Eles chegam ao hotel na condição de exilados, desalojados, sem data prevista para o checkout. O tempo prolongado que passam no hotel vai transformá-los em residentes permanentes que, com vista a uma apropriação ainda que precária e temporária do seu espaço, desenvolvem ruses habitacionais (CERTEAU, 2004), subvertendo a sua lógica funcional. O hotel, vendido na indústria do lazer e dos negócios como "a casa longe de casa", torna-se, de facto, casa para várias famílias de retornados, que rapidamente acabarão por rebelar-se contra as regras tão rigidamente estabelecidas. Desenvolvem-se ficções paralelas, delimitam-se microespaços habitacionais, onde têm lugar micro-estratégias

\footnotetext{
12 "A memória da Shoah - e a literatura do testemunho de um modo geral - desconstrói a historiografia tradicional (e também os tradicionais géneros literários) ao incorporar elementos antes reservados à ficção. A leitura estética do passado é necessária, pois opõe-se à 'musealização' do ocorrido, ela está vinculada a uma modalidade da memória que quer manter o passado ativo no presente. Ela quer apresentar, expor o passado, seus fragmentos, ruínas e cicatrizes" (SELIGMANN-SILVA, 2003, p. 57).

13 " $[. .$.$] highly charged with emotion and value, the chronotope of the$ threshold, it can be combined with the motif of encounter, but its most fundamental instance is as the chronotope of crisis and break in a life" (BAKTHIN, 1981, p. 248).
} 
de apropriação, à imagem de cada hóspede, à escala de cada quarto. Realizam-se plenários com os representantes dos trabalhadores e dos retornados, fritam-se chamuças no quarto da família moçambicana, são organizados churrascos no jardim. O hotel transforma-se numa espécie de residência colectiva, de república anárquica; ele, que é simbolicamente o modelo de um estado de limbo, cenário privilegiado de narrativas que abordam momentos de crise política, pós-guerra, e de questionamento identitário - como é também o do retorno -, revela assim a sua natureza vazia, através da sua ocupação transgressora. Deixam-se marcas de habitação onde não é suposto que elas existam e usam-se as instalações do hotel para um fim que não foi previsto, logo, este território fica saturado de temporalidade e de espacialidade. Isto é, se o hotel, pela sua impessoalidade, se caracteriza como lugar dos novos desalojados da época moderna e contemporânea (cf. KRACAUER, 1995, p. 175; MATTHIAS, 2006, p.41), neste romance, pelo contrário, ele é o lugar de um excesso de vivências. Assim, o hotel pode ser simultaneamente uma casa na qual se aprende a viver, para que seja possível pensar um futuro:

Enquanto não vamos para a América, temos de aceitar este quarto e esta varanda de onde se vê o mar como a nossa casa. É a única maneira de seguir em diante [...] Um quarto pode ser uma casa e este quarto e esta varanda de onde se vê o mar é a nossa casa. A prova disso é que a mãe está lá dentro a fazer naperons e a minha irmã está a estudar para o ponto que vai ter na quarta-feira. (CARDOSO, 2011, p. 164-165)

"Um quarto pode ser uma casa e este quarto é a nossa casa" é uma frase repetida várias vezes por Rui e que, até pela sua própria repetição, não deixa de ser a construção de uma ideia que não compreende, mas na qual quer acreditar. Rui, quando pensa no hotel, recusase a considerá-lo como um espaço/tempo de imobilidade na sua vida; pelo contrário, esforça-se por entendêlo como um momento que se insere na lógica de uma viagem identitária, de um trânsito existencial. Se, por um lado, se desenvolvem mecanismos de auto-sugestão e de prática do quotidiano - estratégias de sobrevivência derivadas da necessidade de acreditar em alguma coisa no meio de tantas mentiras e ilusões -, a verdade é que, tanto Rui como os outros retornados, chegam ao hotel sem saber para onde serão conduzidos em seguida. Todos se perpetuam neste espaço sem perspectivas de futuro, convertendo-se paradoxalmente o hotel no palco de um enraizamento na precariedade. Nesta confluência e oposição de percepções dos diferentes usos do hotel, como numa espécie de dialogismo que cruza a dimensão espacial com a temporal e a discursiva, Rui aproxima-se de um estado de desenvolvimento intelectual que lhe permite compreender que não há só uma versão da história, nem apenas uma forma de a construir e, sobretudo, que muitas vezes ela só é passível de ser interpretada através dos seus fragmentos e das suas ruínas.

O hotel de $O$ retorno assume-se assim como uma heterotopia ${ }^{14}$ que se caracteriza pela "justaposição" e pela "heterocronia" associadas a um estado de "desvio" (FOUCAULT, 1984), na medida em que constitui um lugar reservado aos indivíduos que se encontram em estado de crise em relação à ordem social: os habitantes deste hotel de cinco estrelas não são "hóspedes normais," nem viajantes comuns à procura de um alojamento temporário. O hotel, neste romance, e no contexto do retorno dos portugueses das ex-colónias, é um lugar de asilo e exílio, assemelhando-se a um campo de refugiados de guerra. É também o território colectivo que, enquanto substituto da casa, reúne e justapõe diversos espaços individuais e familiares. Finalmente, é ainda um local possuidor de uma temporalidade própria, que não é partilhada pela sociedade em que se insere, pois constitui um espaço em que o ritmo e as regras do tempo são moldados pelo impasse a que os retornados se viram sujeitos. Associada a esta heterotopia está também, por isso, a experiência da espera que justifica estas estratégias de produção do quotidiano no hotel. Sem perspectivar o futuro e à espera do regresso do pai, Rui testemunhará a erupção de um tempo vago e interminável: "Não sabia que os dias podiam ser tão compridos como os dias de aqui são, o sol fica tempos e tempos a ameaçar que se vai embora e não vai" (CARDOSO, 2011, p. 105). Este tempo caracteriza-se simultaneamente pela suspensão e pela continuidade, sendo um elemento que se insere na lógica da interrupção e, paradoxalmente, da duração. Enquanto novo elemento de provação que se soma ao percurso de obstáculos atravessado por Rui, este longo tempo de espera permitir-lhe-á consolidar um processo de amadurecimento identitário.

O tempo da espera, segundo Schweizer (2005), é justamente um tempo "vazio", pois é dotado de uma temporalidade vaga: situa-se entre o tédio e o desejo. A este intervalo associa-se, contudo, a percepção da duração, esse verdadeiro tempo do ser que, na teoria de Bergson, está latente sob o tempo regulado pela vida social e económica. No seu estudo sobre a espera, Schweizer sugere que este intervalo faz ressurgir esse tempo essencial, potenciando uma experiência e uma maior consciência existencial, o que, de alguma forma, dá lugar ao estranhamento em relação à ordem normal

\footnotetext{
14 "Mais ce qui m'intéresse, ce sont, parmi tous ces emplacements, certains d'entre eux qui ont la curieuse propriété d'être en rapport avec tous les autres emplacements, mais sur un mode tel qu'ils suspendent, neutralisent ou inversent l'ensemble des rapports qui se trouvent, par eux, désignés, reflétés ou réfléchis" (FOUCAULT, 1984).
} 
da vivência humana e às formas estéticas ou poéticas que as traduzem:

In the experience of waiting, I suggest, we awaken to the repressed rhythms of duration and thus also to the deeper dimensions of our being. If in these dimensions we find ourselves estranged from the world in which we live, Gaston Bachelard and Georges Poulet add to that estrangement yet another one - an aesthetic estrangement. (SCHWEIZER, 2005, p. 778)

O tempo da duração, por oposição ao tempo cronológico, é o tempo vivido que não é mesurável. Ora, se pensarmos na espera como uma suspensão do tempo quantitativo em que, por outro lado, sobressai o tempo qualitativo, o hotel descrito neste romance pode ser considerado um espaço de espera existencial, que interrompe o tempo quantitativo da ação, essencial à reflexão e ao desenvolvimento interior do protagonista Rui. Contudo, sendo um cronótopo marcado pela ambivalência espacial e temporal, não deixa de ser, pela sua contradição, um microcosmos que transmite insegurança e medo, variações do mesmo estranhamento já identificado no seu discurso e aqui sublinhado:

[...] não vamos ficar na metrópole muito tempo, vamos embora logo que o pai chegue. O pai vai chegar. Não posso ter medo que o pai nunca chegue. [...] Está muito frio. Muito. Mas o que me faz tremer é o medo, cerro os dentes com muita força e tento não pensar no pai, tenho de pensar noutras coisas [...]. (CARDOSO, 2011, p. 143-144)

[...] Não consigo viver à espera que o pai chegue. Ninguém consegue viver sempre à espera de uma coisa assim. (CARDOSO, 2011, p. 154)

O cruzamento discursivo e as associações de ideias que marcam já as primeiras impressões de Rui ao deixar Angola complexificam-se no tempo da espera que, pela sua natureza reflexiva, é permeável às dúvidas e aos conflitos decorrentes da polifonia que assomou o seu discurso. A auto-sugestão e a contaminação presentes no seu relato, associados aos processos retóricos da repetição e da justaposição, concentram-se numa mise en abyme espacial que, ao invés de sugerir uma fermentação e síntese de diferenças, sublinha, de forma mais evidente, a sua existência e incompatibilidade. É sobre a dúvida relativa ao regresso da figura tutelar do pai que Rui constrói a sua memória, num contínuo acto de transgressão de fronteiras cujas flutuações temporais, espaciais e discursivas dão conta da destabilização das dicotomias, implicando um estado identitário em devir. Rui tem de sobreviver ao pai, a Luanda, tem de acostumar-se ao frio da metrópole e à "mentira" que subjaz às palavras. A narrativa de
Dulce Maria Cardoso, colocando o relato de Rui sob o signo da espera e alojando-o na (des)territorialidade do hotel, dá conta das diferentes versões da realidade que não se anulam, mas que se multiplicam e se debatem, posicionando a construção da memória e da identidade na imanência do discurso, que reproduz o a dilatação da temporalidade na sua natureza de interrupção e continuidade. Como afirma Schweizer,

[t]he rhythms of syntax, the ambiguities and paradoxes of figurative language, the polyphonies of narrative form leave a trace of the inward heterogeneous, fluid temporality of the self. In this way, Bergson claims, 'He [the novelist] has brought us back into our own presence'. (SCHWEIZER, 2005, p. 785)

Em conclusão, O retorno problematiza o percurso da tomada de consciência de estar no mundo, convocando a escrita da memória de Rui e, metonimicamente, dos retornados à sua dimensão presencial, de decantação e filtragem da história colonial, elaborada num exercício de tensão e negociação entre o presente e o passado, entre o "lá" e o "cá", entre o eu e o Outro. Nesse sentido, é pertinente colocar a reflexão sobre a construção da memória num lugar como o hotel, a partir da sua a varanda ou do seu terraço, de onde se vislumbra o mar que distende o espaço e o tempo, entre o regresso de África e o sonho da partida para a América:

Amanhã já não estou aqui. Parece impossível. Parece impossível que o dia de deixar o hotel tenha chegado e que eu tenha medo de sermos outra vez uma família com uma casa. Tenho medo de deixarmos de ser uma família de retornados no hotel e passarmos a ser uma família de retornados entre as famílias de cá. Acho que nunca mais vou ser capaz de pensar e sentir uma coisa de cada vez. Com o tempo devo habituar-me e deixar de me incomodar com isso. Não posso evitar que umas coisas tragam outras. Não deve ter mal. E também não deve fazer mal. Como não faz mal eu não saber o que aconteceu ao pai na prisão, aos demónios da mãe, à Silvana ou ao tio Zé. Nada disso tem mal desde que ainda haja coisas de que eu tenha a certeza. (CARDOSO, 2011, p. 267)

Não se trata neste romance, portanto, de refletir sobre a superação do trauma, mas de problematizar o próprio trauma como presença perturbadora que se renova a cada ensaio da sua estabilização. Esta narrativa, enquanto testemunho, dá conta do "momento de tentativa de reunir os fragmentos dando um nexo e um contexto aos mesmos" (SELIGMAN-SILVA, 2005, p. 85), concentrando-se na imanência da ruína identitária daqueles que sobrevivem à violenta experiência do desenraizamento. Não pode haver um retorno a uma metrópole que nunca antes se tinha 
conhecido, nem a um passado que já se desfez. Existe apenas a possibilidade da gestão do caos e dos ruídos dos retornos repetidos e falhados, através de um exercício de organização dessa realidade desfeita no registo precário da sua presença. Constrói-se a memória como pulsão de sobrevivência e (re)constrói-se metaforicamente a casa com os blocos de cimento que a fábrica do pai de Rui produzirá; porém, sabendo que os seus alicerces serão fundados sobre as mesmas ruínas do singular hotel de cinco estrelas no Estoril, onde " $[\ldots]$ pratos com caravelas desenhadas em mares tumultuosos [...]" e "[...] tapeçarias com índios e marinheiros a assistirem à primeira missa do Brasil [...]" (CARDOSO, 2011, p.91) serviram ironicamente os sobreviventes do grande naufrágio do império. O testemunho de Rui representa alegoricamente a história dos retornados e a história do próprio colonialismo português, que continua ainda hoje a escrever-se no plano instável das memórias e da sua intrínseca e complexa relação com o território, questionando o paradoxo de retornar a um lugar que não se conhece ou já não existe.

\section{Referências}

BACHELARD, Gaston. Poétique de l'espace. Paris: PUF, 1957.

BAKTHIN, Mikhail. Forms of time and the chronotope in the novel. In: HOLQUIST, Michael; EMERSON, Caryl (Ed. e trad.). The dialogic imagination. Austin: University of Texas, 1981. p. 84-258.

CALAFATE RIBEIRO, Margarida. Empire, colonial wars and post-colonialism. Portuguese Studies, v. 18, p. 132-214, 2002.

CARDOSO, Dulce Maria. O retorno. Lisboa: Tinta-da-China, 2011.

CERTEAU, Michel de. L'invention $d u$ quotidien. Paris: Gallimard, 1974. v. 1.

FOUCAULT, Michel. Des espaces autres (conférence au Cercle d'études architecturales, 14 mars 1967). Architecture, Mouvement, Continuité, n. 5, p. 46-49, Oct. 1984. Disponível em: <http://foucault.info/documents/heterotopia/foucault. heterotopia.en.html>. Acesso em: 28 out. 2013.
FREUD, Sigmund. Beyond the pleasure principle. In: PHILLIPS, Adam (Ed.). The Penguin Freud Reader. Londres/ Nova Iorque: Penguin Classics, 2006. p. 221-213.

GOULD, Isabel Ferreira. Decanting the past: Africa, colonialism, and the new portuguese novel. Luso-Brazilian Review, v. 45, n. 1, p. 182-197, 2008.

KRACAUER, Siegfried. The hotel lobby. In: KRACAUER, Sigmund; LEVIN, T. (Ed.). The mass ornament: Weimar essays. Cambridge, London: Harvard University Press, 1995. p. $173-184$.

LACAN, Jacques. Tuché et automaton. In: LACAN, Jaques; MILLER, Jacques-Alain (Ed.). Le séminaire de Jacques Lacan: Livre XI. Paris: Editions du Seuil, 1973. p. 53-61.

MACHADO, Bruno. Os filhos dos "retornados": a experiência africana e a criação de memórias, pós-memórias e representações na pós-colonialidade. Dissertação (Mestrado) - Instituto de Geografia e Ordenamento do Território da Universidade de Lisboa, Lisboa, 2011.

MARTINS, Catarina Isabel. Portugal e o império. Memórias de retorno ou retornos da memória, Vírus - Revista política de ideias, n. 3, série 2, p. 97-103, maio 2013. Disponível em: $<$ http://www.revistavirus.net $>$. Acesso em: 28 out. 2013.

MATTHIAS, Bettina.The hotel as setting in early twentiethcentury german and austrian literature: checking in to tell a story. Nova Iorque: Camden House, 2006.

RIBEIRO, Raquel. (12/08/2010). Os retornados estão a abrir o baú. Disponível em: <http://ipsilon.publico.pt/livros/texto. aspx?id=263209>. Acesso em: 28 out. 2013.

SCHWEIZER, Harold. On waiting. University of Toronto Quarterly, v. 74, n. 3, p. 777-792, Summer 2005.

SELIGMANN-SILVA, Marcio. História, memória, literatura. O testemunho na era das catástrofes. Campinas: Editora da UNICAMP, 2003.

SELIGMANN-SILVA, Marcio. O local da diferença. São Paulo: Editora 34, 2005. 